\title{
Surgery-first orthognathic treatment of an adult patient with unilateral cleft lip-palate and multiple missing teeth: a case report
}

\author{
Hasibe, Baser Keklikci'; Nisa, Gul Amuk'; Alper, Alkan ${ }^{2}$ \\ 1 Department of Orthodontics, Faculty of Dentistry, Erciyes University, Kayseri, Turkey. \\ 2 Department of Oral and Maxillofacial Surgery, Faculty of Dentistry, Bezmialem Vakif University, Istanbul, Turkey.
}

\begin{abstract}
Introduction: The comprehensive treatment approach and outcomes of a patient with cleft lip and palate was presented in this case report.

Case presentation: A 31-year-old man with unilateral cleft lip and palate(UCLP) had a chief complaint of his mandibular prognathism and asymmetric smile. His clinical and radiographic evaluation showed a Class III skeletal relationship, multiple missing teeth, mandibular anterior occlusal canting, $6 \mathrm{~mm}$ of negative overjet and $16 \mathrm{~mm}$ overbite. "Surgery first orthognathic approach" was planned including, short-term orthodontic treatment, maxillary advancement and segmental mandibular subapical osteotomy.
\end{abstract}

Conclusion: At the end of the treatment, a functional occlusion, a harmonious profile, and patient satisfaction were achieved.

Baser Keklikci H, Gul Amuk N, Alkan A. Surgery-first orthognathic treatment of an adult patient with unilateral cleft lip-palate and multiple missing teeth: a case report South Eur J Orthod Dentofac Res. 2018;5(1):19-24.

Submitted: Decemebr 23, 2018; Revised: April 6, 2019; Published: May 5, 2019

\section{INTRODUCTION}

Cleft lip and palate (CLP) is the most common congenital craniofacial deformity in which the facial structures are unable to merge correctly due to various factors during the embryological period. ${ }^{1}$ CLP is associated with maxillary sagittal, transversal, and vertical discrepancies. ${ }^{2,3}$ The treatment of these patients is often carried out by the multidisciplinary approach of various branches of medicine and dentistry. ${ }^{4,5}$

The conventional approach for correction of severe dentofacial anomalies consists of presurgical orthodontic treatment, surgical treatment and postsurgical orthodontic finishing. ${ }^{6}$ Orthodontic treatment before orthognathic surgery reveals the true skeletal discrepancy preoperatively ${ }^{7}$ and helps to determine the required dental decompensations which would otherwise

Corresponding Author:

Hasibe Baser Keklikci

Department of Orthodontics,

Faculty of Dentistry, Erciyes University,

38039 Melikgazi, Kayseri, Turkey

e-mail: hasibebaser91@gmail.com limit fully correcting the skeletal deformity. ${ }^{8}$ Surgery-First Approach (SFA) which is defined as starting with the surgery with no presurgical orthodontic procedure and the orthodontic treatment is performed postoperatively. ${ }^{9-11}$ The concept of this technique which includes direct surgical intervention or minimal tooth decompensation for a few months preoperatively aims the rapid improvement of facial esthetic that is usually the patient's chief complaint at the beginning of the treatment. ${ }^{12}$

This case report presents the treatment process and outcomes of an adult patient who had unilateral lip-palate deformity and multiple missing teeth, treated with "surgery first approach" in cooperation with the orthodontist and oral and maxillofacial surgeon.

\section{CASE REPORT}

A 31-year-old man with operated nonsyndromic unilateral CLP referred to the orthodontic clinic of Erciyes University in Kayseri, Turkey. He had a chief complaint of his mandibular prognathism and smile asymmetry. He had received primary lip repair and palatoplasty in the first year of life and did not 
undergo bone grafting. His profile was concave with a retruded upper lip and a protruded lower lip (Figure 1A, 1B). He had nasal deviation but no apparent mandibular asymmetry (Figure 1C). His intraoral examination showed anterior and posterior bilateral crossbites, severe anterior deep bite and a deep curve of Spee (Figure 1D, 1E, 1F). In the mandible, there was occlusal plane canting, with the left side tipped downward by $3 \mathrm{~mm}$ (Figure 1E). The clinical and radiographic evaluation showed that the patient had multiple missing teeth and prosthetic rehabilitation of lower incisors (Figure 2A). The lateral cephalometric radiograph analysis showed a Class III skeletal relationship $\left(\mathrm{ANB},-3.5^{\circ}\right)$ related with maxillary retrusion (SNA, 76.7 $\mathrm{SNB}, 80.5^{\circ}$ ), standard vertical dimensions (SNGoGn, 31.7 ; y-axis, $\left.57.4^{\circ}\right), 6 \mathrm{~mm}$ of negative overjet, $16 \mathrm{~mm}$ overbite, -11.7 $\mathrm{mm}$ of the upper lip to $\mathrm{E}$ plane distance and $-0.9 \mathrm{~mm}$ of lower lip to E-plane distance (Figure 2B).

The patient's medical and dental histories were unremarkable, with no family occurrences reported. No previous orthodontic treatment had been performed, and no signs or symptoms of the temporomandibular joint disorder.

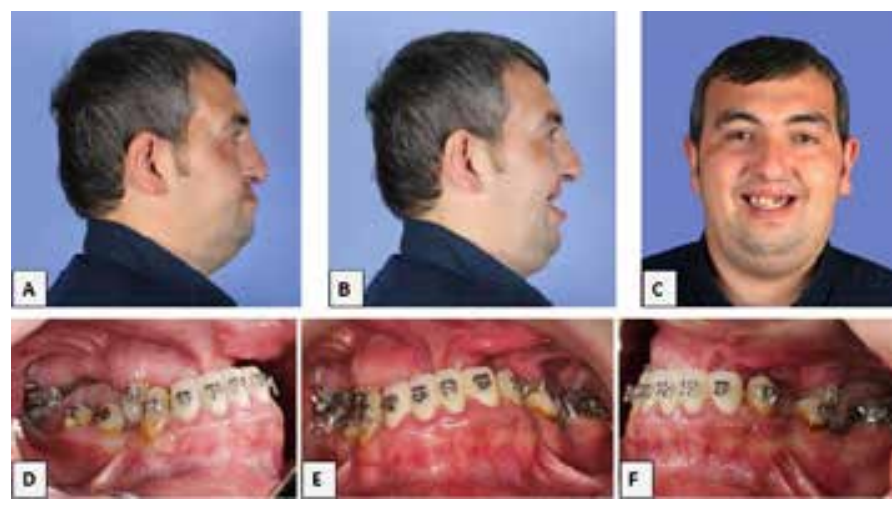

Figure 1. Pretreatment extraoral and intraoral photographs of the patient. A) Profile view. B) Profile view while smiling. C) Frontal view. D) Right intraoral view. E) Frontal intraoral view. F) Left intraoral view.

\section{Treatment plan and progress}

The treatment objectives were to improve the midfacial deficiency associated with the skeletal class III relationship, to improve the chewing function by correcting the crossbite and anterior deep bite and to improve the asymmetrical smile appearance caused by mandibular teeth.

Because of the multiple missing teeth 'surgery first' approach was planned. Orthodontic bonding was performed with 0.018"x0.025" edgewise brackets (Roth, American Orthodontics Mini Master, Sheboygan, WI USA) with the purpose of short-term leveling of present teeth in order to prevent the primer contact during surgery and facilitating the surgical splint fixation. The surgical archwires were applied in 3 parts of the lower jaw to allow for segmental surgery.
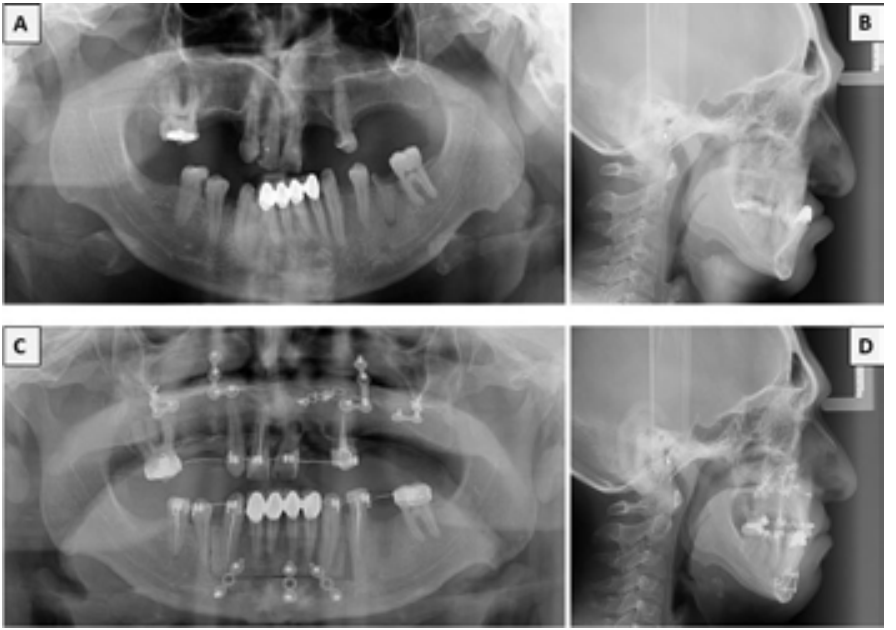

Figure 2. Pretreatment and posttreatment panoramic and cephalometric radiographs. A) Pretreatment panoramic radiograph. B) Pretreatment lateral cephalometric radiograph. C) Posttreatment panoramic radiograph. D) Posttreatment lateral cephalometric radiograph.

Orthognathic surgery was planned as two jaw surgery and was conducted at Department of the Oral and Maxillofacial Surgery in Erciyes University. For upper jaw, $6 \mathrm{~mm}$ advancement and $1 \mathrm{~mm}$ impaction with Le Fort 1 osteotomy was planned, while segmental surgery with anterior subapical osteotomies was intended for the lower jaw. At the segmental osteotomy of anterior mandible, the vertical osteotomy line was marked distally from the teeth 33 and 43 , and the horizontal osteotomy line was marked $2 \mathrm{~mm}$ apically of the anterior teeth. The anterior segment was marked with a pencil to be impacted 3 $\mathrm{mm}$ on the left and $0 \mathrm{~mm}$ on the right to correct the canting of the occlusal plane (Figure 3A). This anterior dentoalveolar segment was also placed $2 \mathrm{~mm}$ posteriorly (Figure $3 \mathrm{~B}$ ).

After surgery, the bracket positions were corrected and rebonded. The existing teeth were aligned orthodontically. Orthodontic leveling was completed in a short time (6 months). Then, 4 dental implants were applied to the upper jaw and 1 dental implant was applied to the lower jaw.
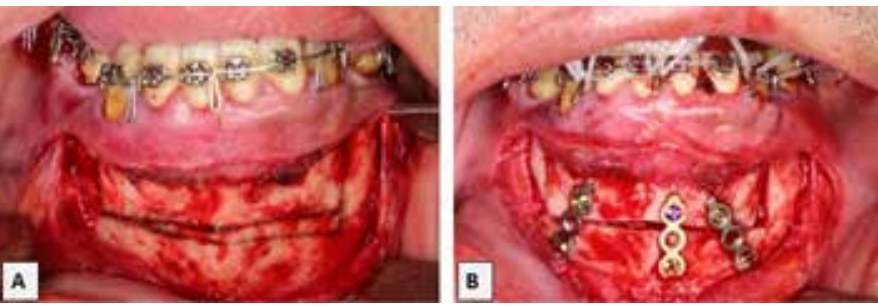

Figure 3. Intraoperative appearance of the mandibular anterior dentoalveolar segment. A) Marked view of the bone to be removed B) Reposition view of the mandibular anterior dentoalveolar segment. 


\section{Radiographic evaluation}

All x-rays were taken with the same device and by the same technician while the patient was in the natural head position. Panoramic $\mathrm{x}$-rays were taken with the 1.3 magnification coefficient with the Instrumentarium OP200 (Kavo Dental, Tuusula, Finland) and the lateral cephalometric x-rays with 1.2 magnification coefficient with the Instrumentarium OP300 (Kavo Dental, Tuusula, Finland).

Lateral cephalometric and panoramic films were taken and analyzed at the beginning of treatment (T0, Figure 2A, 2B) and after orthognathic surgery (T1, Figure 2C, 2D). Skeletal, dental, lip, airway, velum palatinum, nasal tip, columella and subnasale measurements were performed on lateral cephalometric films (Figure 5A, 5B). Occlusal canting measurements were performed on the panoramic films (Figure 5C). The reference points used and all measurements made are shown in Table $1 \mathrm{~A}$.
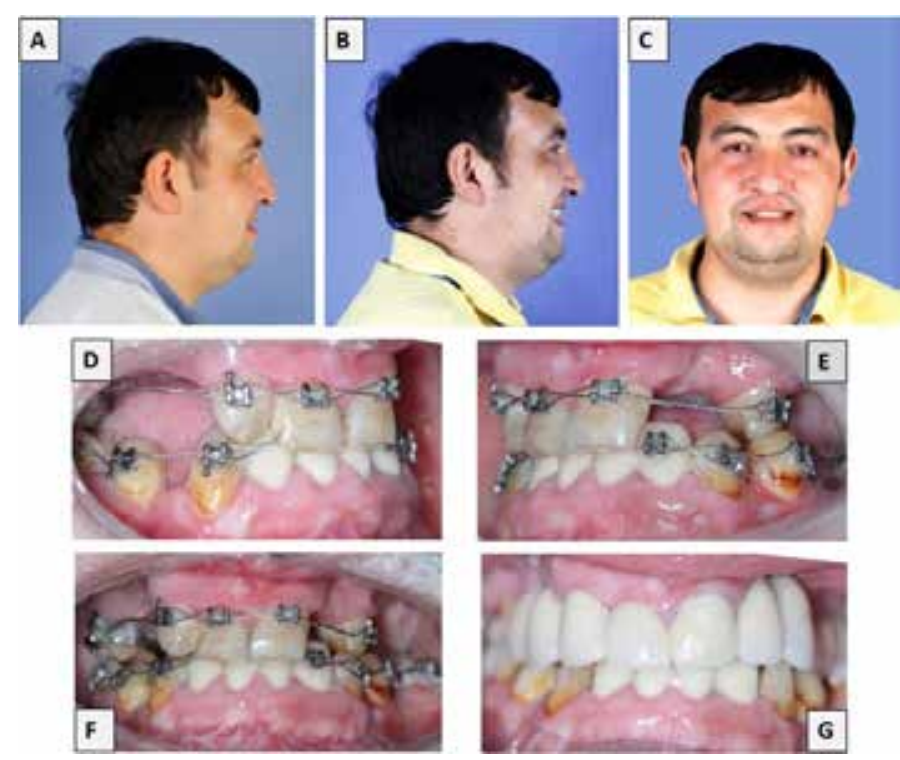

Figure 4. Posttreatment extraoral and intraoral photographs of the patient. A) Profile view. B) Profile view while smiling. C) Frontal view. D) Right intraoral view. E) Left intraoral view. F) Frontal intraoral view. G) Temporary prosthesis restoration.

\section{Treatment results}

Evaluation and comparison of pretreatment and posttreatment measurements were presented in Table 1B.

The protrusion of his lower lip was corrected and his facial profile was improved (Figure 4A, 4B). He had a symmetrical smile (Figure 4C). The anterior crossbite was corrected, and normal overjet $(4 \mathrm{~mm})$ and overbite $(3 \mathrm{~mm})$ were achieved (Figure 4D, 4E, 4F). Temporary prosthesis restoration was applied to the upper and lower dentition (Figure 4G).

The distances of the mandibular canine teeth to the horizontal reference plane were changed from $4.2 \mathrm{~mm}$ to $1 \mathrm{~mm}$ and mandibular anterior canting was corrected. (Figure 2C)
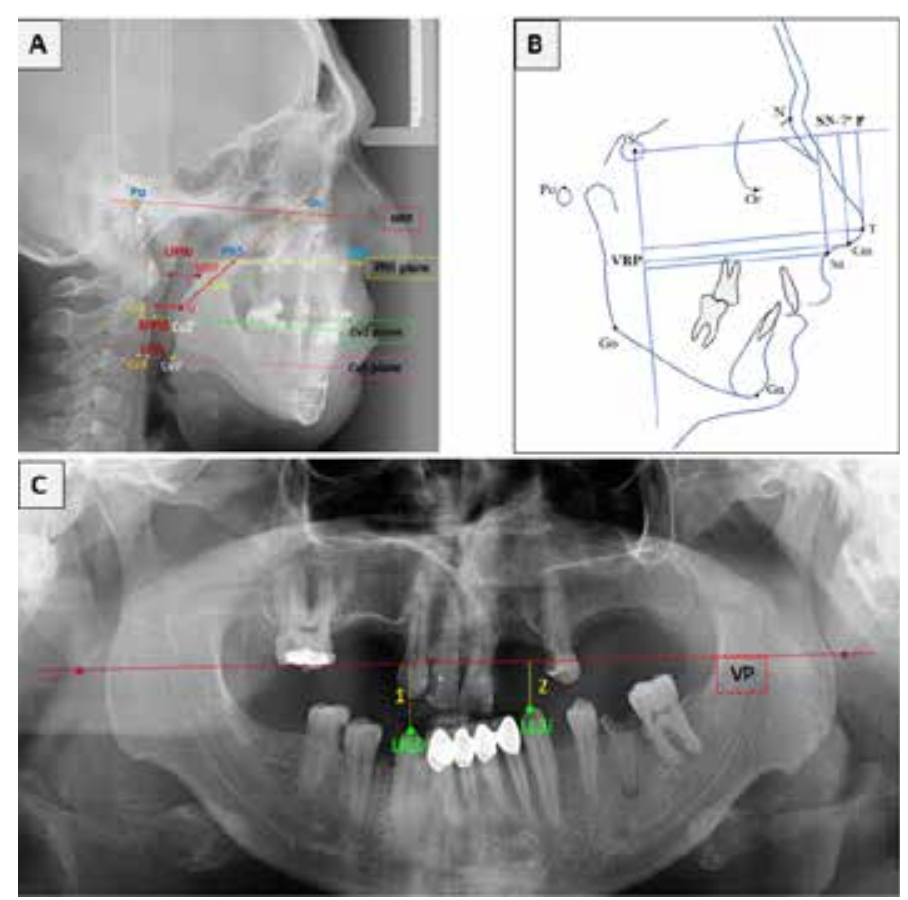

Figure 5. Schematic representations. A) Schematic view of airway and velum palatinum measurements. B) Schematic view of the nasal tip, columella and subnasale measurements. C) Schematic view of occlusal canting measurement.

At the lateral cephalometric evaluation, the angle of ANB increased from $-3,5^{\circ}$ to $2.3^{\circ}$ (SNA, 80.1 ${ }^{\circ}$; SNB, $77.8^{\circ}$ ). According to plane $\mathrm{E}$, the upper lip came to $1.8 \mathrm{~mm}$ forward and the lower lip $1.1 \mathrm{~mm}$ backward. Upper face height decreased, lower face height increased and total face height increased slightly within normal limits. The nasolabial angle was highly developed and increased by $36.9^{\circ}$ to $88.5^{\circ}$. Subnasale forward and downward, columella and the tip of the nose have moved forward and upward (Figure 2D). Due to the existing prosthetic bridge restoration, the angles of the lower incisors could not be changed.

\section{DISCUSSION}

The "surgery first" approach in orthognathic surgery was presented in 2009 by Nagasaka et al. ${ }^{10}$ with a case report of a patient with a skeletal class III malocclusion without orthodontic preparation. In the "surgery first" approach, it is thought that, increased blood flow and bone turnover as the results of Regional Acceleratory Phenomenon (RAP) provides acceleration in the speed of tooth movement during the healing process. ${ }^{12,13}$ The researchers stated that this new treatment approach could be a frequently used procedure in the future due to the excellent clinical results and a significant reduction in total treatment time. ${ }^{10}$ The final occlusion can be difficult to predict, so the clinician's experience and skill are crucial to achieving satisfactory results. ${ }^{13-15}$ For this case 'surgery first 


\begin{tabular}{|c|c|}
\hline Reference Points & Description \\
\hline A & A point \\
\hline $\mathrm{B}$ & B point \\
\hline$S$ & Sella \\
\hline $\mathrm{N}$ & Nasion \\
\hline Go & Gonion \\
\hline Gn & Gnathion \\
\hline Sn & Subnasale \\
\hline $\mathrm{Cm}$ & Columella \\
\hline $\mathrm{T}$ & Tip of the nose \\
\hline ANS & Anterior nasal spine \\
\hline PNS & Posterior nasal spine \\
\hline PPW & Posterior pharyngeal wall \\
\hline UPW & Upper pharyngeal wall (intersection point of PNS plane and posterior pharyngeal wall) \\
\hline MPW & Middle pharyngeal wall (intersection of the Cv2 plane and posterior pharyngeal wall) \\
\hline LPW & Lower pharyngeal wall (intersection of the Cv3 plane and posterior pharyngeal wall) \\
\hline $\mathrm{U}$ & The most inferior and posterior point of uvula \\
\hline MVP & Middle point of posterior border of velum palatinum \\
\hline Cv2 & The most inferior and anterior point of second cervical vertebra \\
\hline Cv2' & İntersection point of $\mathrm{Cv} 2$ plane and anterior pharyngeal wall \\
\hline Cv3 & The most inferior and anterior point of third cervical vertebra \\
\hline Cv3' & İntersection point of $\mathrm{Cv} 3$ plane and anterior pharyngeal wall \\
\hline LR3i & The most incisal point of the lower right third teeth \\
\hline LL3i & The most incisal point of the lower left third teeth \\
\hline Intr & It refers to the $r$ \\
\hline Reference Planes & Description \\
\hline HRP & Horizontal Reference Plane, The plane constructed by line between Po-Or (Frankfurt Horizontal Plane) \\
\hline PNS plane & The plane passing through posterior nasal spine and anterior nasal spine \\
\hline $\mathrm{SN}-7^{\circ} \mathrm{P}$ & $7^{\circ}$ plane to SN Plane \\
\hline VRP & Vertical Reference Plane (Perpendicular plane to $\mathrm{SN}-7^{\circ} \mathrm{P}$ ) \\
\hline Cv2 plane & The plane parallel to Frankfurt Horizontal Plane and passing through Cv2 \\
\hline Cv3 plane & The plane parallel to Frankfurt Horizontal Plane and passing through Cv3 \\
\hline VP & The plane between of the most inferior points of the second cervical vertebras in the panoramic $x$-ray \\
\hline Measurements & Description \\
\hline N-ANS & Upper face height, distance between $\mathrm{N}$ and ANS \\
\hline ANS-Gn & Lower face height, distance between ANS and Gn \\
\hline N-Gn & Total face height, distance between $\mathrm{N}$ and $\mathrm{Gn}$ \\
\hline Y-axis & Angle between horizontal reference plane and S-Gn plane \\
\hline 1 & The perpendicular distance between LR3i and VP \\
\hline 2 & The perpendicular distance between LL3i and VP \\
\hline Occlusal canting & Difference between 1 and 2 \\
\hline U-PNS & Velum palatinum length \\
\hline VPT & Velum palatinum thickness \\
\hline HRP/U-PNS & Angle between horizontal reference plane and velum palatinum \\
\hline PPW-U & Distance between PPW and U (Parallel to HRP) \\
\hline PPW-MVP & Distance between PPW and MVP (Parallel to HRP) \\
\hline Sn-VRP & Perpendicular distance from $S n$ to VRP \\
\hline Sn- $\left(\mathrm{SN}-7^{\circ} \mathrm{P}\right)$ & Perpendicular distance from $\mathrm{Sn}$ to $\mathrm{SN}-7^{\circ}$ Plane \\
\hline Cm-VRP & Perpendicular distance from $\mathrm{Cm}$ to VRP \\
\hline $\mathrm{Cm}-\left(\mathrm{SN}-7^{\circ} \mathrm{P}\right)$ & Perpendicular distance from $\mathrm{Cm}$ to $\mathrm{SN}-7^{\circ}$ Plane \\
\hline T-VRP & Perpendicular distance from T to VRP \\
\hline $\mathrm{T}-\left(\mathrm{SN}-7^{\circ} \mathrm{P}\right)$ & Perpendicular distance from $\mathrm{T}$ to $\mathrm{SN}-7^{\circ}$ Plane \\
\hline
\end{tabular}

Table 1A. Definitions of reference points, reference planes and measurements. 


\begin{tabular}{|c|c|c|c|}
\hline Variable & Pre-treatment (T0) & Post-treatment (T1 & Difference \\
\hline SNA $\left(^{\circ}\right)$ & 76.7 & 80.1 & 2.4 \\
\hline $\operatorname{SNB}\left({ }^{\circ}\right)$ & 80.5 & 77.8 & -2.7 \\
\hline $\mathrm{ANB}\left({ }^{\circ}\right)$ & -3.5 & 2.3 & 5.8 \\
\hline Overjet (mm) & -6 & 4 & 10 \\
\hline Overbite $(\mathrm{mm})$ & 16 & 3 & -13 \\
\hline Upper lip to E-Plane (mm) & -11.7 & -9.9 & 1.8 \\
\hline Lower lip to E-Plane (mm) & -0.9 & -2 & -1.1 \\
\hline N-ANS (mm) & 54 & 51.4 & -2.6 \\
\hline ANS-Gn (mm) & 60.7 & 70.6 & 9.9 \\
\hline $\mathrm{N}-\mathrm{Gn}(\mathrm{mm})$ & 114.7 & 122 & 7.3 \\
\hline Nasolabial angle $\left({ }^{\circ}\right)$ & 36.9 & 88.5 & 51.6 \\
\hline SN-GoGN $\left({ }^{\circ}\right)$ & 31.7 & 35.6 & 3.9 \\
\hline Y-axis $\left({ }^{\circ}\right)$ & 57.4 & 62.9 & 5.5 \\
\hline Occlusal canting (mm) & 4.2 & 1 & -4.1 \\
\hline UPW-PNS (mm) & 23.8 & 25 & 1.2 \\
\hline MPW-Cv2' (mm) & 15.0 & 11.8 & -3.2 \\
\hline LPW-Cv3' (mm) & 12.8 & 13.3 & 0.5 \\
\hline U-PNS (mm) & 27.8 & 28.5 & 0.8 \\
\hline $\mathrm{VPT}(\mathrm{mm})$ & 10.6 & 11 & 0.4 \\
\hline HRP/U-PNS $\left({ }^{\circ}\right)$ & 130.3 & 139.1 & 8.8 \\
\hline PPW-U (mm) & 10.7 & 10.1 & -0.6 \\
\hline PPW-MVP (mm) & 10.7 & 10.6 & -0.1 \\
\hline Sn-VRP (mm) & 50.7 & 51.7 & 1 \\
\hline $\mathrm{Sn}-\left(\mathrm{SN}-7^{\circ} \mathrm{P}\right)(\mathrm{mm})$ & 66.8 & 73.3 & 6.5 \\
\hline $\mathrm{Cm}-\mathrm{VRP}(\mathrm{mm})$ & 52.1 & 50.9 & -1.2 \\
\hline $\mathrm{Cm}-\left(\mathrm{SN}-7^{\circ} \mathrm{P}\right) \quad(\mathrm{mm})$ & 84.5 & 86.2 & 1.7 \\
\hline T-VRP (mm) & 47.6 & 46.4 & -1.2 \\
\hline $\mathrm{T}-\left(\mathrm{SN}-7^{\circ} \mathrm{P}\right) \quad(\mathrm{mm})$ & 91.0 & 91.9 & 0.9 \\
\hline
\end{tabular}

Table 1B. Evaluation and comparison of pretreatment and posttreatment measurements.

approach' was preferred in order to correct the chief complaint of the patient at the beginning of the treatment and to rapidly improve the facial aesthetics. Besides, the number of missing teeth did not permit the proper pre orthodontic preparation.

Patients with cleft lip and palate, tooth deficiencies and tooth shape anomalies are frequently seen in the area near the cleft site. In addition, due to scar tissue, it may also occur due to maxillary constriction and posterior crossbite. ${ }^{16}$ So CLP patients, faced with aesthetic, morphological, and functional problems in the dentofacial region frequently. Many methods may be used to improve mid-face deficiency, such as Le Fort I osteotomy, distraction osteogenesis (DO) and maxillary anterior segmental DO. ${ }^{17-19}$ Distraction osteogenesis requires high cooperation of the patient; the patient should provide adequate oral hygiene and he must comply with screw turning protocol. Also, a second surgical procedure is required to remove the screw in the DO. Le Fort I osteotomy was preferred in this patient due to its relatively simple, less invasive nature and the low level of patient's cooperation. In addition, the amount of activation was not much because of double jaw surgery planning. There are a few case reports which stated worsening of velopharyngeal insufficiency after maxillary advancement. ${ }^{20-22}$ In this case, the measurements regarding velopharyngeal, oropharyngeal and hypopharyngeal areas on lateral cephalometric films showed that distance between the middle point of posterior border of velum palatinum (MVP) and posterior pharyngeal wall (PPW) decreased by $0.1 \mathrm{~mm}$ (almost unchanged), distance between uvula $(\mathrm{U})$ and posterior pharyngeal wall (PPW) decreased by $0.6 \mathrm{~mm}$, although distance between the upper point of velum palatinum (posterior nasal spine, PNS) and upper pharyngeal wall (UPW) increased. In addition, the velum palatinum length and width increased after the surgery. This situation was interpreted with the rise in U-PNS/HRP angle which means the backward movement of velum palatinum related to the backward force of tongue after mandibular anterior set back surgery. The distance between the upper pharyngeal wall (UPW) and posterior nasal spine (PNS) increased by $1.2 \mathrm{~mm}$, the distance between the middle pharyngeal wall (MPW) and $\mathrm{Cv} 2$ ' decreased by $3.2 \mathrm{~mm}$, the distance between the lower pharyngeal wall (LPW) and Cv3' increased by $0.5 \mathrm{~mm}$. In the light of these measurements and clinical examination which showed improvement in speech ability revealed that there was no insufficiency after maxillary advancement in this case. 
Anterior segmental osteotomy is indicated if the movement of the anterior teeth is necessary but it can not be done for some reasons, such as the periodontal health of the teeth is insufficient, the amount of movement of the teeth is high, long duration of treatment. ${ }^{23}$ In this case, segmental surgery was preferred instead of mandibular set-back because the submandibular tissue was drooping, pogonion was insufficient on a profile, airway volume reduction was not desired and the occlusal plane canting was originating from the mandibular anterior region. As with all dentoalveolar osteotomies, there is a risk of apical root lesions, loss of vitality in the teeth and periodontal pockets formation. ${ }^{24-26}$ Unlike other dento-alveolar osteotomies, the devascularization of the segment is extremely rare due to the large and thick muscles in the lingual side. In this operation, no complications were observed thanks to highly qualified and experienced surgeons performing several similar surgical procedures.
After the segmental surgery, significant improvement was observed in the protrusive position of the lower lip and thus in the profile.

\section{CONCLUSIONS}

At the end of treatment, skeletal Class III malocclusion was treated, significant improvement in facial appearance was achieved, overjet and overbite were provided in sufficient amount for prosthetic rehabilitation to be performed. The surgery-first treatment approach provided successful results with an improvement of jaw relationships, chewing function and facial aesthetics in adult CLP patients.

\section{CONFLICT OF INTEREST}

The authors declare no conflict of interest.

\section{REFERENCES}

1. Karaman A. Non-sendromik yarık dudak ve/veya damak deformitesi. Med Med J. 2009;24(3):134-7.

2. Baek SH, Moon HS, Yang WS. Cleft type and Angle's classification of malocclusion in Korean cleft patients. Eur J Orthod. 2002;24(6):647-53.

3. Vettore MV, Sousa Campos AE. Malocclusion characteristics of patients with cleft lip and/or palate. Eur J Orthod. 2010;33(3):311-7.

4. Robin, N. H., Baty, H., Franklin, J., Guyton, F. C., Mann, J., Woolley, A. L., ... \& Grant, J. (2006). The multidisciplinary evaluation and management of cleft lip and palate. South Med J. 99(10), 1111-1121.

5. Cohen, M. (2004). Residual deformities after repair of clefts of the lip and palate. Clin Plast Surg. 31(2), 331-345.

6. Montian Manosudprasit D, Tasanee Wangsrimongkol D, Palakorn Surakunprapha M, Poonsak Pisek D. Surgery first orthognathic approach for skeletal class III malocclusion corrections-a literature review. J Med Assoc Thai. 2012;95(11):S172-S80.

7. Sabri R. Orthodontic objectives in orthognathic surgery: state of the art today. J World Fed Orthod . 2006;7(2).

8. Grubb J, Evans C. Orthodontic management of dentofacial skeletal deformities. Clin Plast Surg. 2007;34(3):403-15.

9. Epker BN, Fish LC. Surgical-orthodontic correction of open-bite deformity. Am J Orthod Dentofacial Orthop . 1977;71(3):278-99.

10. Nagasaka H, Sugawara J, Kawamura H, Nanda R. " Surgery first" skeletal Class III correction using the Skeletal Anchorage System. J Clin Orthod. 2009;43(2):97.

11. Villegas C, Uribe F, Sugawara J, Nanda R. Expedited correction of significant dentofacial asymmetry using a "surgery first" approach. J Clin Orthod. 2010;44(2):97-103.

12. Liou EJ, Chen P-H, Wang Y-C, Yu C-C, Huang C, Chen Y-R. Surgeryfirst accelerated orthognathic surgery: orthodontic guidelines and setup for model surgery. J Oral Maxillofac Surg. 2011;69(3):771-80.

13. Kim JH, Mahdavie NN, Evans CA. Guidelines for "surgery first" orthodontic treatment. Orthodontics-Basic Aspects and Clinical Considerations: InTech; 2012.

14. Baek S-H, Ahn H-W, Kwon Y-H, Choi J-Y. Surgery-first approach in skeletal class III malocclusion treated with 2-jaw surgery: evaluation of surgical movement and postoperative orthodontic treatment. J Craniofac Surg. 2010;21(2):332-8.
15. Liao Y-F, Chiu Y-T, Huang C-S, Ko EW-C, Chen Y-R. Presurgical orthodontics versus no presurgical orthodontics: treatment outcome of surgical-orthodontic correction for skeletal class III open bite. Plast Reconstr Surg. 2010;126(6):2074-83.

16. Ranta R. A review of tooth formation in children with cleft lip/palate. Am J Orthod Dentofacial Orthop . 1986;90(1):11-8.

17. Hirata K, Tanikawa C, Aikawa T, Ishihama K, Kogo M, Iida S, et al. Asymmetric anterior distraction for transversely distorted maxilla and midfacial anteroposterior deficiency in a patient with cleft lip/palate: Twostage surgical approach. Cleft Palate Craniofac J. 2016;53(4):491-8.

18. Kloukos D, Fudalej P, Sequeira-Byron P, Katsaros C. Maxillary distraction osteogenesis versus orthognathic surgery for cleft lip and palate patients. The Cochrane Library. 2016.

19. Kageyama-Iwata A, Haraguchi S, Iida S, Aikawa T, Yamashiro T. Maxillary anterior segmental distraction osteogenesis to correct maxillary deficiencies in a patient with cleft lip and palate. Cleft Palate Craniofac J. 2017;54(4):465-73.

20. Guyette TW, Polley JW, Figueroa A, Smith BE. Changes in speech following maxillary distraction osteogenesis. Cleft Palate Craniofac J. 2001;38(3):199-205.

21. Satoh K, Nagata J, Shomura K, Wada T, Tachimura T, Fukuda J, et al. Morphological evaluation of changes in velopharyngeal function following maxillary distraction in patients with repaired cleft palate during mixed dentition. Cleft Palate Craniofac J. 2004;41(4):355-63.

22. Nohara K, Tachimura T, Wada T. Prediction of deterioration of velopharyngeal function associated with maxillary advancement using electromyography of levator veli palatini muscle. Cleft Palate Craniofac J. 2006;43(2):174-8.

23. Park JU, Hwang Y-S. Evaluation of the soft and hard tissue changes after anterior segmental osteotomy on the maxilla and mandible. J Oral Maxillofac Surg. 2008;66(1):98-103.

24. Pepersack WJ. Tooth vitality after alveolar segmental osteotomy. J Oral Maxillofac Surg. 1973;1:85-91.

25. Kwon H-J, Pihlstrom B, Waite DE. Effects on the periodontium of vertical bone cutting for segmental osteotomy. J Oral Maxillofac Surg. 1985;43(12):952-5.

26. Schultes G, Gaggl A, Kärcher H. Periodontal disease associated with interdental osteotomies after orthognathic surgery. J Oral Maxillofac Surg. 1998;56(4):414-7. 